\title{
International Comparative Analysis of Higher Education Expenditure Performance Evaluation
}

\author{
Honglei Zhang ${ }^{1}$, Fengyu Wang ${ }^{1}$, Zhenbo Zang ${ }^{2}$ \\ ${ }^{1}$ College of Finance and Economics, Yangtze Normal University, China; \\ ${ }^{2}$ City College of Science and Technology, Chongqing University, China.
}

Key words: Higher education, Expenditure performance, Industry development.

\begin{abstract}
At present, our higher education and economic growth are suffering from a profound structural contradiction, or rather, the talents cultivated in colleges/universities are always hard to satisfy the needs of industry development, regardless of a huge government investment in the higher education. Under such a background, this paper has, taking Brazil, India and Russia as an example, studied their models of higher education, made a comparative analysis on their performance evaluation methods of higher education, and sought the important factors affecting the expenditure performance of higher education, giving advice to the construction of our fiscal expenditure performance evaluation system for higher education. It is expected that such advice can improve the expenditure performance of higher education, guide the institutions of higher education to adapt their expenditure to the industry development, and boost the competitiveness of our higher education.
\end{abstract}

\section{Introduction}

Since the 21 st century, with the economic development in China, there has been a large demand gap of senior talents every year, which is hard to be satisfied with our existing higher education system. Since the reform of higher education at the turn of this century, our scale of higher education has expanded dramatically, with higher education arriving at the stage of popularization; every year, millions of college/university graduates flood into the labor market, resulting in great employment pressure, which has become an issue of widespread concern. Targeted at the structural contradiction between higher education output and the demand for talents, it is undoubtedly an effective solution to develop a scientific and efficient evaluation system for expenditure performance of higher education in line with China's national conditions. This paper has analyzed the performance evaluation models of higher education in Brazil, India and Russia whose economic development levels are similar to China's economic development level, in the hope of providing experience to the establishment of our evaluation system for expenditure performance of higher education.

\section{Overview of Expenditure Performance Evaluation on Higher Education in Brazil, India and Russia}

\subsection{Brazil's Evaluation Model for Expenditure Performance of Higher Education.}

Since the 1980s, Brazil Government has, with a view to guaranteeing the development of higher education resources quality and scale, improved unceasingly the building of its expenditure performance evaluation system for higher education based upon the practical experience gained from Western countries, and formed its unique expenditure performance evaluation system for higher education. [1]

\subsubsection{Principle of Performance Evaluation}

In the expenditure evaluation of higher education, Brazil has currently adhered to the guidelines of fairness and efficiency, strived to avoid the interference of artificial factors in the actual performance evaluation, and rallied support from stakeholders, so as to achieve the harmony and win-win; meanwhile, it is essential to seek efficiency while protecting the educational fairness, the development of which is facilitated with efficiency. In terms of concrete practice, it is sponsored by 
the government, and participated in jointly by the Institute of Education and professional associations.

\subsubsection{Expenditure Evaluation Index System of Higher Education.}

According to the expenditure evaluation system of higher education established as per Brazilian Federal Law (2004), Brazil's evaluation index system of expenditure performance for higher education is made up of the national ability level test for college/university students, evaluation of college/university resources and college/university quality survey.

The national ability level test for college/university students is made up of written examination and questionnaire. The written examination includes liberal education and specialized knowledge, the former highlights the examinees' cognition to the current situation in Brazil, in the world and other domains as well as morality and ethics etc., and the latter focuses on their mastery and application to the relevant expertise. The questionnaire is made up of the examinees' personal details (mainly including their socioeconomic background variables, for example, family economic status, parents' details and personal information) and their views on testing items (mainly including their views on the test mode, difficulty of test subjects and availability of such test, etc.).

The index system for evaluation of university resources mainly includes the curriculum system and the evaluation system of colleges and universities. The curriculum system belongs to the internal evaluation, essentially including teaching resources, teachers' level, construction of teaching facilities and teaching organization means etc., focusing on whether the available resources per capita in the colleges and universities can satisfy the needs for teaching activities. The evaluation system of colleges and universities belongs to the external evaluation, primarily focusing on the social efficacy of colleges and universities, reflecting their contribution to the society, whether their graduates and scientific research activities conform to the economic and social development requirements etc.

Since 1980, the college/university quality survey is conducted once a year, involving all colleges/universities nationwide, with college/university teachers and students enrolled as the respondents. The key indicators include the financial situation of colleges/universities, the number of students enrolled in all programs, the proportion of enrollments and actual enrolments, the number of degrees awarded, personal details of student admissions, teachers' titles and degree statuses, the setting and learning statuses of elective courses, etc.

\subsubsection{Specific Evaluation Method.}

The national ability level test for college/university students is organized by the Ministry of Education, with all professional associations, education associations and other relevant organizations participating in jointly to form the Examination Board. Before the test, the Examination Board will, by referring to the prior evaluation report of level test, identify the contents and evaluation standards of the current level test, and then organize such a test. The name lists of students taking the test are provided by the colleges/ universities, and students are required to take the written examination across the country at the same time. The Examination Board will assign observers to patrol. Before the test, students will get the test syllabus sent down by the Ministry of Education. The main test method is written examination, including open-ended questions and multiple-choice questions, which are designed to examine the examinees' general knowledge and expertise level; the student's score is determined by his/her relative position in the scores of all examinees, falling into grade $\mathrm{A}$ to $\mathrm{E}$ based on the average of scores. In the questionnaire, depending on their enrollment years and majors, students are in different entrance ranks, which are to be standardized, and the student's rank divided by the total number of students stands for the relative rank of all students.

The evaluation of college/university resources is organized triennially by the higher education sectors. Prior to the evaluation, specialists are selected to evaluate the curriculum, teaching, scientific research and hardware facilities of colleges/ universities. Upon receipt of the evaluation data from the specialists, the higher education sectors will make processing and analysis to such data as per the preset standards, and submit the results to the National Board of Education for further analysis and final evaluation. 
Internet questionnaire is used to gather information for college/university quality survey. Prior to the survey, the National Institute of Education calls together experts from all disciplines to analyze the questionnaire a year before and prepare the questionnaire for the current year. After the survey, experts make comprehensive evaluation to the obtained data. Then, the Ministry of Education submits the analysis results to the Federal Government, who accordingly lays down the expenditure policy for higher education, and simultaneously reveals such results on the Internet.

\subsubsection{Use of Evaluation Results.}

Since its implementation, Brazil's performance evaluation of higher education has provided a standard for the evaluation of colleges/universities and discipline assessment, exerted an important effect on the fast-growing higher education, and furnished detailed data for scholars to study the Brazil's higher education outputs. Meanwhile, the performance evaluation results have also provided a basis for the national allocation of financial contribution, enhancing the use efficiency of national educational fund.

Colleges/universities have also taken the performance evaluation results of higher education as their basis for operation, in particular those private colleges/universities, adjusted the subject setting and specialty construction depending on the evaluation results, and tried to attract students with the evaluation results and ranking.

After the announcement of performance results, students may choose the top-ranked disciplines and colleges/universities.

\subsection{India's Evaluation Model for Expenditure Performance of Higher Education.}

To ensure the improved expenditure performance of higher education, India has, since 1994, founded the National Association of Career Colleges (NACC) to assume the performance evaluation of all colleges/universities nationwide. After the development and improvement for over 20 years, NACC has formed a relatively scientific and well-established evaluation system in terms of principle, index system, method and application of results, etc. [14]

\subsubsection{Evaluation Principle.}

To assure the considerable operability and wide acceptability of performance results, NACC has specified the performance evaluation principles, including objectivity, reliability, credibility, adaptability, purposiveness and teamwork.

\subsubsection{Performance Evaluation Index.}

Based on the prior evaluation experience and by drawing on the advanced experience of international expenditure performance evaluation for higher education, NACC has, since April 2007, enacted and implemented the Performance Appraisal System of Tertiary Institutions and New Evaluation Method, and set 7 benchmarks for the expenditure performance evaluation of higher education. The Performance Appraisal System of Tertiary Institutions and New Evaluation Method has expounded the weight details of different performance evaluation key points in each benchmark, elaborated the data information (Table 1), and enhanced the operability of performance evaluation.

\subsubsection{Performance Evaluation Method.}

In terms of specific implementation of performance evaluation, NACC has practiced two evaluation methods in view of the present co-existence of home colleges/universities and affiliated institutes. All affiliated institutes put into force the two-step performance evaluation method of the evaluation of qualifications and NAAC comprehensive performance evaluation, while colleges/universities, autonomous institutes and key institutes get directly into the one-step performance evaluation method of NACC comprehensive performance evaluation.

In the evaluation of qualifications, all affiliated institutes are expected to apply for IEQA before their application to the NAAC comprehensive performance evaluation.

In the NAAC comprehensive performance evaluation, NACC takes a series of measures to perfect the performance evaluation system, specifically setting reasonably the benchmarking of performance evaluation key points, identifying the appropriate weights of all performance evaluation key points, adjusting the existing 9-level evaluation into four-level evaluation from $\mathrm{A}$ to $\mathrm{D}$, and converting the 
existing percentage into the cumulative grade point average (CGPA). After getting the CGPA, all participating institutions of higher education will obtain a corresponding grade, score representation and judging position, to signify their performance evaluation situations.

Finally, the peer evaluation panel of experts will, with detailed field survey, discussion and analysis, generate a written report with respect to the features and defects of tertiary institutions after tabling rational proposals for better performance evaluation of colleges/universities. After the survey, the peer review experts will submit the CGPAs of tertiary institutions and the written report to NACC, and NACC will, based on the written report, issue to each tertiary institution an evaluation certificate, which is valid for 5 years, and once expired, a new round of performance evaluation and identity evaluation will go on.

Table 1. Performance Evaluation Benchmarks, Key points and Their Practical Weights in the Performance Appraisal System of Tertiary Institutions and New Evaluation Method

\begin{tabular}{|c|c|c|c|c|}
\hline \multirow[b]{2}{*}{ Performance evaluation benchmarks } & \multirow[b]{2}{*}{ Performance evaluation keypoints } & \multicolumn{3}{|c|}{ Weight details of keypoints } \\
\hline & & $\begin{array}{c}\text { Colleges/ } \\
\text { universities }\end{array}$ & $\begin{array}{c}\text { Autonomous } \\
\text { institutes }\end{array}$ & $\begin{array}{l}\text { Affiliated } \\
\text { institutes } \\
\end{array}$ \\
\hline \multirow{5}{*}{ 1. Curriculum setting and development } & 1.1 Scenario of curriculum setting & 90 & 50 & 10 \\
\hline & 1.3 Market response to the curriculum & 10 & 10 & 10 \\
\hline & 1.4 Curriculum innovation situation & 10 & 10 & 5 \\
\hline & $\begin{array}{c}1.5 \text { Practice and application of theoretical knowledge in } \\
\text { the curriculum }\end{array}$ & 10 & 10 & 10 \\
\hline & Subtotal of weights & 150 & 100 & 50 \\
\hline \multirow{7}{*}{ 2. Teaching and performance evaluation } & 2.1 Enrollment way and students qualification & 20 & 30 & 30 \\
\hline & 2.2 Adaptation to instructional needs & 20 & 35 & 45 \\
\hline & 2.3 Launching situation of teaching activities & 90 & 170 & 270 \\
\hline & $\begin{array}{l}\begin{array}{c}2.4 \text { Teachers' education background and qualification } \\
\text { level }\end{array} \\
\end{array}$ & 60 & 65 & 65 \\
\hline & 2.5 Teaching evaluation activities and innovation & 50 & 40 & 30 \\
\hline & 2.6 Practice and application of teaching evaluation & 10 & 10 & 10 \\
\hline & Subtotal of weights & 250 & 350 & 450 \\
\hline \multirow{7}{*}{$\begin{array}{l}\text { 3. Scientific research, consulting and } \\
\text { popularization }\end{array}$} & 3.1 Development situation of scientific research & 40 & 30 & 15 \\
\hline & 3.2 Level of scientific research results & 90 & 50 & 25 \\
\hline & 3.3 Situation of consulting activities & 20 & 10 & 5 \\
\hline & 3.4 Popularization activities of scientific research & 30 & 40 & 40 \\
\hline & 3.5 Collaboration situation of scientific research & 10 & 10 & 5 \\
\hline & $\begin{array}{l}\text { 3.6 Practice and operation of scientific research } \\
\text { development, consulting and popularization }\end{array}$ & 10 & 10 & 10 \\
\hline & Subtotal of weights & 200 & 150 & 100 \\
\hline \multirow{7}{*}{$\begin{array}{l}\text { 4. Hardware equipment } \& \text { facilities and } \\
\text { software equipment \& facilities }\end{array}$} & 4.1 Situation of hardware equipment \& facilities & 20 & 20 & 20 \\
\hline & $\begin{array}{l}\text { 4.2 Maintenance situation of hardware equipment \& } \\
\text { facilities }\end{array}$ & 10 & 10 & 10 \\
\hline & 4.3 Situation of library holdings & 35 & 35 & 35 \\
\hline & $\begin{array}{l}\text { 4.4 Application of information and communication } \\
\text { technology }\end{array}$ & 15 & 15 & 15 \\
\hline & 4.5 Other equipment $\&$ facilities & 10 & 10 & 10 \\
\hline & $\begin{array}{l}\text { 4.6 Practice and application of hardware equipment \& } \\
\text { facilities and software equipment \& facilities }\end{array}$ & 10 & 10 & 10 \\
\hline & Subtotal of weights & 100 & 100 & 100 \\
\hline \multirow{5}{*}{ 5. Educatees' development and support } & 5.1 Situation of educatees' development & 30 & 30 & 30 \\
\hline & 5.2 Educatees' support & 30 & 30 & 30 \\
\hline & 5.3 Situation of educatees' activities & 30 & 30 & 30 \\
\hline & $\begin{array}{c}\text { 5.4 Practice and operation of educatees' support and } \\
\text { development }\end{array}$ & 10 & 10 & 10 \\
\hline & Subtotal of weights & 100 & 100 & 100 \\
\hline \multirow{7}{*}{$\begin{array}{l}\text { 6. Governance and guidance of tertiary } \\
\text { institutions }\end{array}$} & 6.1 Development vision of tertiary institutions & 15 & 15 & 15 \\
\hline & $\begin{array}{l}\text { 6.2 Organizational management situation of tertiary } \\
\text { institutions }\end{array}$ & 20 & 20 & 20 \\
\hline & $\begin{array}{c}\text { 6.3 Development strategy and conception of tertiary } \\
\text { institutions }\end{array}$ & 30 & 30 & 30 \\
\hline & 6.4 Personnel governance of tertiary institutions & 40 & 40 & 40 \\
\hline & $\begin{array}{l}\text { 6.5 Financial and resources governance of tertiary } \\
\text { institutions }\end{array}$ & 35 & 35 & 35 \\
\hline & $\begin{array}{c}\text { 6.6 Practice and operation of governance and guidance of } \\
\text { tertiary institutions }\end{array}$ & 10 & 10 & 10 \\
\hline & Subtotal of weights & 150 & 150 & 150 \\
\hline \multirow{5}{*}{ 7. Innovation means } & $\begin{array}{l}\text { 7.1 Performance evaluation system within the tertiary } \\
\text { institutions }\end{array}$ & 20 & 20 & 20 \\
\hline & 7.2 Detailed ways of innovation & 15 & 15 & 15 \\
\hline & $\begin{array}{l}7.3 \text { Interaction, communication and collaboration with } \\
\text { stakeholders }\end{array}$ & 15 & 15 & 15 \\
\hline & Subtotal of weights & 50 & 50 & 50 \\
\hline & Total weight & 1000 & 1000 & 1000 \\
\hline
\end{tabular}




\subsubsection{Use of Performance Evaluation Results.}

NACC performance evaluation results are aligned with the allocation of government financial investment by India's University Grants Committee; only on the premise of accepting the performance evaluation and identity evaluation can the institutions of higher education get the government financial support on education. Under such a condition, the institutions of higher education will make continuous self-improvement to win the government's financial support on higher education, ensuring the smooth proceeding of basic teaching activities. The public will also make a choice of higher education, according to the NACC performance evaluation results and identity evaluation. Further, employers will select excellent talents in reference to the NACC performance evaluation results and identity evaluation of graduate institutions. NACC will also adjust the performance evaluation benchmarks every five years depending on the domestic development level of higher education, thereby ensuring the integral improvement of higher education level.

\subsection{Russia's Evaluation Model for Expenditure Performance of Higher Education.}

After entering into the 21th century, Russia has, targeted at the expenditure performance evaluation problem of higher education, issued a series of documents, and implemented a series of reformation measures, ensuring by law the national inputs to the expenditure performance evaluation of higher education, and boosting the development of expenditure performance of higher education. [13]

\subsubsection{Evaluation Principle.}

Russia has renovated its performance evaluation system of higher education, which is prominently manifested in the organization, operation and guarantee mechanisms.

In terms of organization mechanism, multiple agencies are in collaborative operation, including the National Council for Higher Education Accreditation, National Accreditation Board, National School Certification Supervision Office, National Accreditation Center (NAC) and NAC database, etc. Such agencies have different functions and cooperate with each other in the performance evaluation of higher education.

In terms of operating mechanism, Russia has, since January 2000, gradually practised the comprehensive evaluation mechanism of higher education, which merges the approval, certification and accreditation into an integral whole and remains the evaluation characteristics of each link. The comprehensive evaluation is carried out intensively, with evaluation results valid for three years; it is required to perform the approval, certification and accreditation again three years later.

In terms of guarantee mechanism, Russia has formulated the guarantee systems from four aspects of planning, management, resources and enhancement, ensuring the smooth launching of expenditure performance activities for higher education.

\subsubsection{Evaluation Index.}

Compared with the traditional expenditure performance evaluation of higher education, the existing comprehensive evaluation has the following changes: 1 . ascending the status of science-method activities in the expenditure performance evaluation system of higher education, and paying attention to the application of innovation means in the higher education activities; 2 . raising the requirements of comprehensive college/universities in the educational syllabus scope, graduate education, and proportion of graduate students; 3. paying more attention to the quality training of educatees, in particular the graduate education; 4. scientific research activities are still an important evaluation content of colleges/universities, which have even higher requirements in scientific research funds and monograph research achievements.

\subsubsection{Evaluation Method.}

Russia's existing evaluation procedure for expenditure performance of higher 
Table 2. Evaluation and Identification Indexes for Types of Colleges/Universities

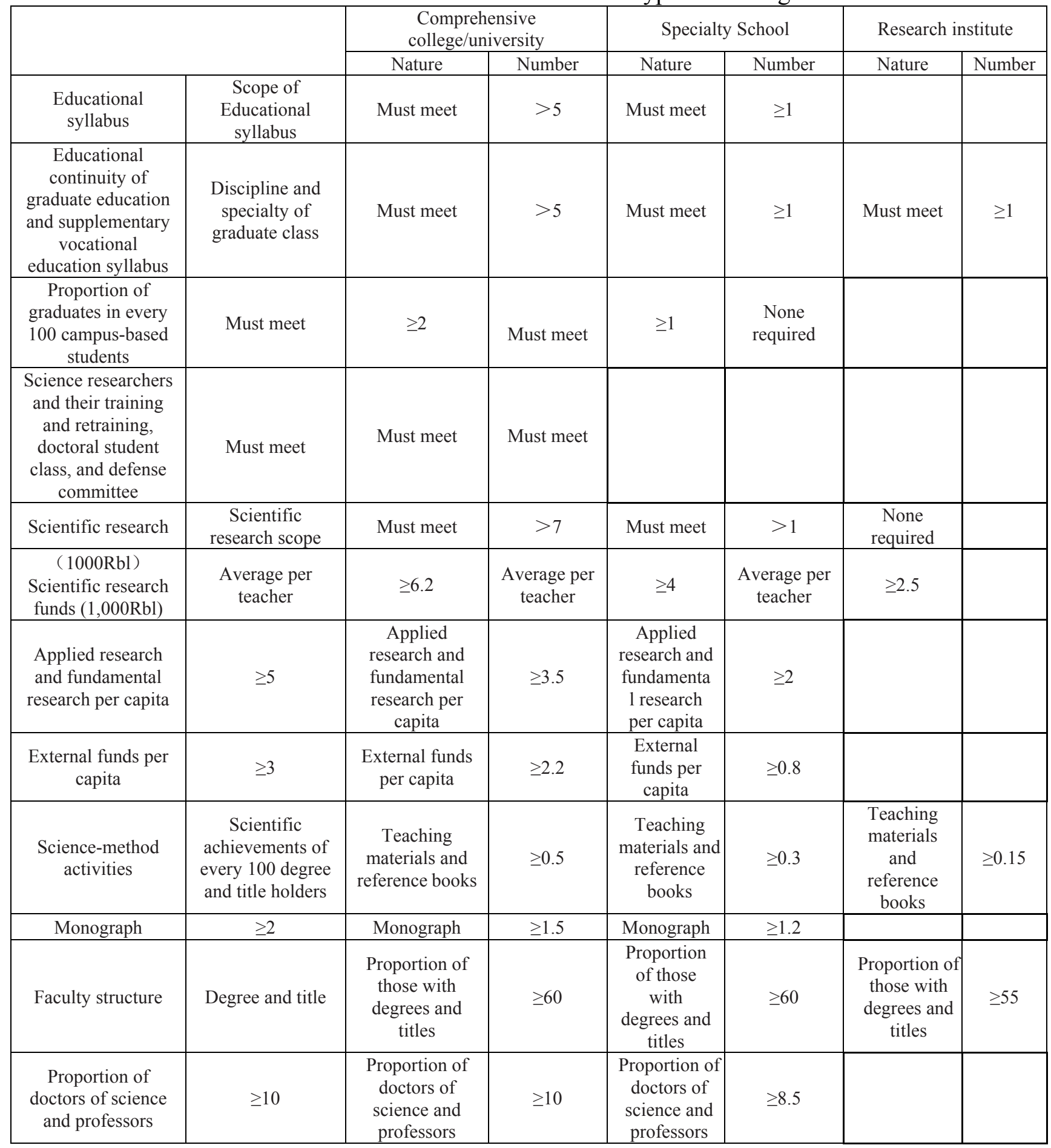

Education includes approval and identification, the former is permission to higher education activities, and the latter is an external evaluation to the implementation situation of national education standards. Besides, the centralized comprehensive evaluation can minimize effectively any repetitive work, curtail the evaluation practice, increase the evaluation experts' investigation practice to tertiary institutions, and enhance the evaluation efficiency and effects.

\subsubsection{Use of Evaluation Results.}

Thanks to the reform of expenditure performance evaluation of higher education, Russia's degree certificates of domestic colleges/universities have been recognized by European countries, and Russian students may work or study in other European countries, facilitating the Russian education system to be integrated in the European higher education system. Russia has, based on the expenditure performance evaluation results of higher education, appropriated the education budget, which is more competitive, stimulates colleges/universities to constantly improve the scientific 
research and teaching level, and increases the fund utilization efficiency. It is essential to carry out extensive regulation to the expenditure performance of higher education, continually adjust the specialty structure of higher education, and revise the catalog of disciplines to meet the needs of economic and social development.

\subsection{Comparison of Evaluation Models for Expenditure Performance of Higher Education in}

\section{Brazil, India and Russia.}

By comparing the evaluation models for expenditure performance of higher education in Brazil, India and Russia, it can be found that such three countries are led by government sectors, set up specialized performance evaluation organizations and issue special legal documents to ensure the successful undertaking of performance evaluation activities. The financial funds on education in these countries are allocated based on the evaluation results for expenditure performance of higher education, thereby enhancing the domestic competitiveness of higher education and the utilization efficiency of financial funds on education.

However, subject to different beginning levels and development statuses of higher education, these three countries have different emphases in the expenditure performance evaluation of higher education: Brazil's evaluation pays more attention to the fairness of higher education, with particular emphasis on the equity for students to access to higher education; India's evaluation sets different evaluation standards for a variety of tertiary institutions, laying emphasis on the integral elevation of domestic higher education level; characterized by a high starting point of higher education, Russia's evaluation focuses more on the scientific research ability and graduate education of tertiary institutions, and driving the domestic higher education to further be integrated into the European higher education system.

\subsection{Enlightenments from Evaluation Models for Expenditure Performance of Higher} Education in Brazil, India and Russia.

From the analysis and comparison on the evaluation models for expenditure performance of higher education in the three countries, we are enlightened as follows:

The expenditure performance evaluation of higher education should be protected by legal documents, and initiated by the special government agencies. It is necessary to make a reasonable evaluation cycle, so that the performance evaluation index system adapts to the changes of national development requirements of higher education, avoiding the rigid development model of higher education arising from fixed indexes. The expenditure performance evaluation results of higher education should be announced to the public, to guide the flow of students, and accept the supervision and comments from all sectors of the society.

\section{Acknowledgements}

The authors thanks the support of the Chinua Project Cooperation Research Project of the Ministry of Education (Grant No: S2015060); the support of Advanced Education Scientific Research Project of Chongqing Higher Education Society (Grant No: CQGJ13B342); the support of Chongqing Education Science Planning Project (Grant No: 2014-GX-043).

The authors thanks the support of the Science and Technology Research Program of Chongqing Municipal Education Commission (Grant No: KJ1709235); the support of Chongqing Social Science Planning PhD Program (Grant No: 2016BS115).

\section{References}

[1]. Universities, Organizational Structure of the Research Activity and the Spin-off Formation: Lessons from Brazilian Case [EB/OL] http:// www.Globelicsacademy.net/ 2008/ 2008_student_ presentations/ Ren-ault_GA08.pdf.

[2]. Schwartzman. The National Assessment of Courses in Brazil [EB/ OL].http: // www.schwartzman.org.br/Simon /provao2.pdf. 
[3]. Zhu Yangon. Comparative Research on the Quality Guarantee System of Higher Education in "BRIC Four Countries"--Based on the Perspective of Government Management [D]. Shanghai Normal University, 2010:83.

[4]. Cybele Yarn Andrade, José Roberto Russ Perez. Strategic Management of the University of Brazil [J]. International Higher Education, 2011(4): 74-75.

[5]. Wang Zheng Qing. Internationalization of Higher Education: Brazil's Countermeasures and Existing Problems [J]. Furan Education Forum, 2008(3): 82-86.

[6]. Shi Longley, Liu Yankee. Unfair Expansion - Examining Brazilian Current Higher Education Policy [J]. Foreign Education Research, 2008 (1): 71-74.

[7]. Goo Bin, Zhang Xiaoping. A Review of Curriculum Assessment in Universities in Brazil from 1996 to 2003[J]. China Higher Education Evaluation, 2008(2): 67-70.

[8]. Liu Xiao Feng. Analysis of Impulse Response of Financial Education Expenditure, Financial Expenditure and Gina Coefficient [J]. Lanzhou Academic Journal, 2012(5):195-201.

[9]. Liu Xiao Feng. Study on the Performance Evaluation of China's Financial Education Expenditure [J]. Assets and Finances in Administration and Institution, 2011(7): 22-27.

[10]. Liu Xiao Feng. Review of Foreign Talent Cultivation [J]. Journal of Yunnan Finance \& Economics University, 2012(3): 50-54.

[11]. Liu Xiao Feng. Performance Evaluation of Higher Education Expenditure of Brazil: Principles, Index System, Method and Application [J]. Morden Education Management, 2014 (2):123-128.

[12]. Liu Xiao Feng. Study on the Development Strategy of Russian Higher Education Expenditure Performance Evaluation System [J]. Journal of Jinzhong University, 2014(2):38-44.

[13]. Liu Xiao Feng. Performance Evaluation of Expenditure in Indian Higher Education: Principles, Index System, Method and Application [J]. Journal of Jinzhong University, 2013(6):28-33. 